\title{
Morte de indigentes no contexto brasileiro: a naturalização do descarte
}

\author{
Raphael Santos Lapa ${ }^{1}$ \\ https://orcid.org/0000-0003-4247-9315
}

\author{
Gilson Matilde Diana ${ }^{2}$ \\ https://orcid.org/0000-0002-9829-6617
}

${ }^{1}$ Universidade de Brasília, Programa de Pós-Graduação em Sociologia, Brasília, DF, Brasil

${ }^{2}$ Academia Nacional de Polícia, Brasília, DF, Brasil

\begin{abstract}
Morte de indigentes no contexto brasileiro: a naturalização do descarte
Resumo: A presente pesquisa consiste na análise do contexto ético expresso por políticas institucionais quanto às mortes tratadas como indigentes em território brasileiro. Buscou-se observar os números e recortes sociais nos dados referentes ao corpo daquele que usualmente é tratado como indesejável. A noção ética aqui se expressa não como um ideal de alcance, mas como constrói-se o juízo de valor moral a partir da noção de indigência, e de como esse elemento naturaliza o descarte daquele que é não propriedade, que pertence, mas não está incluído na sociedade.
\end{abstract}

Palavras-chave: Indigentes. Ética. Agambem

\section{Death of indigents in the Brazilian context: the naturalization of disposal}

Abstract: This paper consists on the analysis of the ethical context expressed by institutional policies regarding the deaths treated as indigent in Brazilian territory. One sought to observe the numbers and social cuts in the data referring to the body of the one who is usually treated as undesirable. The ethical notion here is expressed not as an ideal, but how the moral value judgment is constructed from the notion of indigence, and how this element naturalizes the disposal of those who are not property, who belong, but are not included in society.

Keywords: Indigents. Ethic. Agambem

Recebido em 10.08.2020. Aprovado em 15.12.2020. Revisado em 26.01.2021.

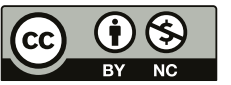

Este é um artigo publicado em acesso aberto (Open Access) sob a licença Creative Commons Attribution NonCommercial, que permite uso, distribuição e reprodução em qualquer meio, sem restrições desde que sem fins comerciais e que o trabalho original seja corretamente citado. 


\section{Introdução}

Indesejável, homo sacer, wargus, bandido, Friedlos ${ }^{1}$ e muitas outras definições têm sido utilizadas para descrever aquele ser que pertence, mas não está incluído em determinada conjuntura social. Trata-se desse ente não desejado, não adaptado, excluído e invisibilizado. É o ser, individual ou coletivo que, por sua condição estruturante, encontra-se como não detentor de determinados direitos. Pertence a uma sociedade, mas não está incluído em seu contexto, seja político, social ou ético.

Fala-se aqui da população em situação de rua, de andarilhos urbanos, de transeuntes no espaço urbano que transmitem o incômodo de seu não pertencimento ao lócus espacial e simbólico da cidade. É acerca de seu fim corpóreo, de seu falecimento e de como o Estado trata esse momento que nos ateremos.

Há matizes e nuances nas classificações de alguém como não desejado ou como inadaptado que não podem ser abandonadas. O não desejado parte do polo exterior. É outrem que não o deseja. É aquele indivíduo que, por sua condição estética, causa o incômodo em nosso espaço urbano. De forma mais detalhada: o indesejado é a imagética do que não se adapta. Este é, assim, em uma linguagem que abarca o contexto econômico liberal, alguém que é não propriedade. Ou seja, não tem propriedade material alguma e não tem sequer a si mesmo como vendedor de sua força de trabalho².

Há o termo do senso geral que termina por chamar essa categoria de invisíveis, o que não se traduz em uma verdade, pois seus corpos estão sempre como um alerta de sua inadaptação. A exclusão é presente e latente aos olhos em tempo contínuo, como nos diz Franklin Leopoldo e Silva (2014, p. 65): "Um sistema pode excluir os elementos contrários à sua funcionalidade, mas um 'sistema' social não pode excluir um indivíduo por sua inadaptação. Ele continua presente na forma da exclusão, que, no limite, é a eliminação".

A construção de uma representação social acerca dos indesejados pode encontrar diversas simbologias a depender do grupo que se analisa. As formas de manutenção simbólicas de inferiorização de migrantes, homossexuais e negros por exemplo, encontram diversos e diferentes instrumentos ao longo da história.

Entretanto, nesta pesquisa pretendemos trazer à análise a existência de determinados elementos morais que naturalizam e legitimam a condição pretérita do indigente. Essa ética ou moralidade, ultrapassa o caráter da ação individual e reverbera inclusive em políticas públicas, ou em suas ausências, quanto às mortes de indigentes ${ }^{3}$.

Esta pesquisa tem por objetivo iniciar o debate sobre estudos referentes ao tratamento dado a óbitos de pessoas classificadas como indigentes, seja pela ausência de reclamantes do corpo, seja pela impossibilidade de identificação. A análise sociológica pode-se estender a uma análise normativa, antropológica ou mesmo filosófica no sentido que se passará a relatar algumas categorias.

\section{A coleta de dados}

A princípio esta pesquisa tinha como delimitação espacial o Distrito Federal. A coleta de dados buscava (i) o perfil sociográfico dos óbitos de cadáveres não identificados ou identificados e não reclamados e (ii) os procedimentos adotados quando da impossibilidade de identificação do corpo. Em um primeiro momento foi realizada consulta no Departamento de Informática do Sistema Único de Saúde (DATASUS), por intermédio do Sistema de Informações de Mortalidade, sistema que realiza a coleta de dados sobre mortalidade no País. A base de dados é fechada ao público, o que ensejou a solicitação via e-SIC da CGU de informação que abarcasse o quantitativo de falecidos em situação de indigência em nível nacional. A resposta oficial ${ }^{4}$ foi simples e objetiva: o SIM não abarca esse tipo de informação.

Na impossibilidade de encontrar os dados em nível nacional, foram realizadas consultas por intermédio do e-SIC do GDF com direcionamento à Polícia Civil do Distrito Federal. Foram solicitados os dados sociográficos com base nos índices básicos dos sistemas do DATASUS: sexo, cor/raça, idade aparente, município etc.

A primeira resposta quanto aos dados sociográficos também foi pela negativa de existência desses elementos, sendo enviado os dados brutos quanto ao número de sepultamentos de pessoas dadas como indigentes, no período de 2010 a $2017^{5}$.

Os procedimentos ${ }^{6}$ para cadáveres não reclamados, por sua vez, foram informados da seguinte maneira: 
PROCEDIMENTOS OPERACIONAIS PADRÃO NO CASO DE CADÁVERES NÃO RECLAMADOS:

- Consultar a data do óbito na Declaração de Óbito dos cadáveres que estão no IML;

Após 5 (cinco) dias do óbito:

- Verificar se o cadáver for identificado, se sim, fazer uma varredura no sistema informatizado (SISTEMAS CORPORATIVOS) à procura de informações a respeito de familiares;

- Em caso positivo, orientar os familiares quanto aos requisitos necessários para retirada do corpo;

Em caso negativo:

- Verificar se o cadáver foi devidamente registrado no SICOLA como CADÁVER NÃO IDENTIFICADO;

- Encaminhar as informações deste corpo à DIVICOM;

- Consultar a Delegacia de Polícia responsável pelo caso se há informações pertinentes à localização de familiares;

- Transcorridos 14 (quatorze) dias, proceder à lavratura do óbito após 15 (quinze) dias; há a necessidade de encaminhar ofício à Vara de Registros Públicos do Distrito Federal, solicitando autorização para lavratura do óbito;

- Encaminhar ofício ao CRAS, anexando a GUIA DE SEPULTAMENTO, solicitando o sepultamento;

- Após 2 (dois) dias úteis, solicitar ao CRAS informações sobre o dia do sepultamento;

- No dia anterior ao sepultamento, informar à equipe do plantão para retirar o cadáver da câmara fria, para descongelamento.

- Com a chegada do carro funerário do Serviço Social, proceder à entrega do corpo.

Para além disso, a resposta última quanto ao perfil sociográfico nos dá um direcionamento acerca do tema que estamos tentando tratar: "[...] podemos afirmar que 90 por cento são do sexo masculino, adulto, moradores de rua e imigrantes predominantemente do Nordeste", a despeito de não haver uma tabulação específica para esse tipo de morte nos sistemas. Sendo assim, no período de 2010 a 2017 obtivemos o quantitativo de pessoas conforme apresentamos no Gráfico 1.

Somente os dados do Distrito Federal, entretanto, demonstraram a dificuldade de acesso a informações básicas sobre o tratamento institucional dado a esses indivíduos. O que desencadeou a curiosidade analítica do alargamento da pesquisa para todo o território nacional.

Nesse sentido, por intermédio da Lei de Acesso à Informação, foram realizados pedidos a todas as Unidades da Federação, o que ensejou em resposta oficial por parte de 17, dentre os 27 totais ${ }^{7}$. 
Gráfico 1 - Quantidade de sepultamentos de indigentes no Distrito Federal ${ }^{21}$

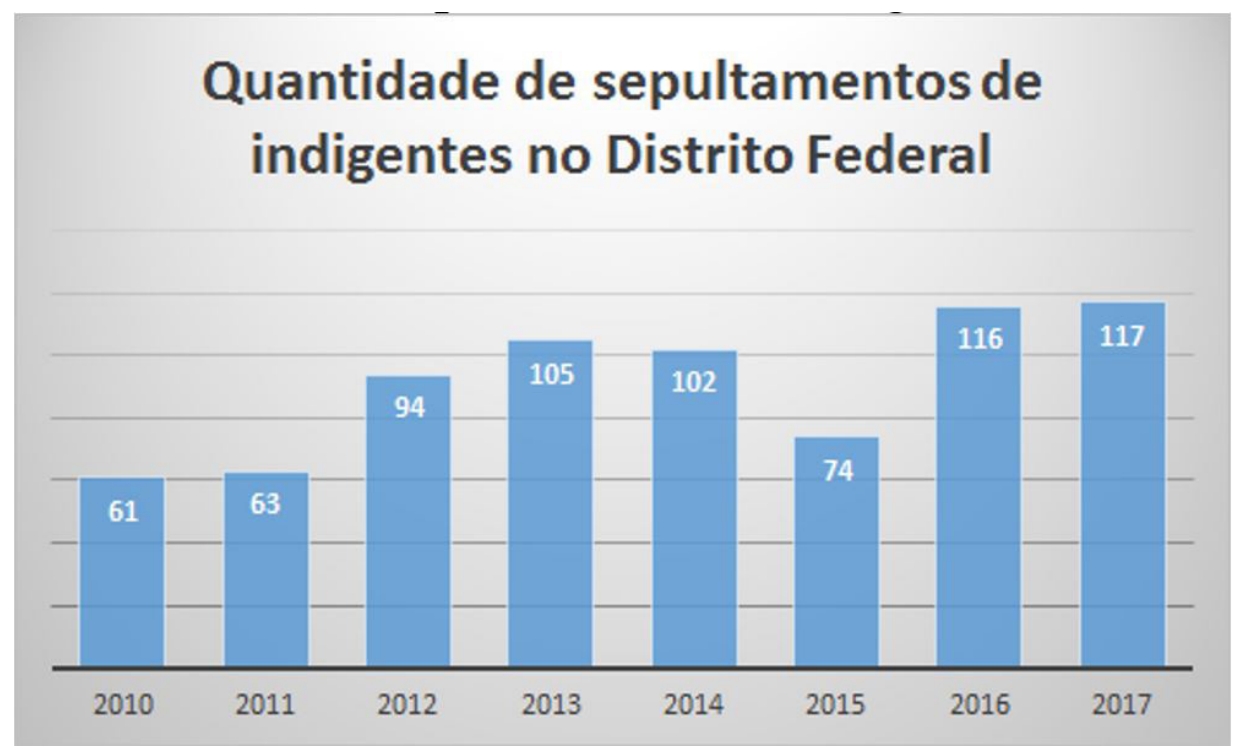

Fonte: Instituto Médico Legal - Distrito Federal. Elaboração Própria

Das 17 Unidades Federativas (UFs) respondentes, somente nove ${ }^{8}$ conseguiram informar os dados sociográficos, conforme indicações na Tabela 1.

Tabela 1 - Dados sociográficos da UFs

\begin{tabular}{|c|c|c|c|c|c|c|c|c|c|c|c|}
\hline \multirow{2}{*}{ UF } & \multirow{2}{*}{2010} & \multirow{2}{*}{2011} & \multirow{2}{*}{2012} & \multirow{2}{*}{2013} & \multirow{2}{*}{2014} & \multirow{2}{*}{2015} & \multirow{2}{*}{2016} & \multirow{2}{*}{2017} & \multirow{2}{*}{2018} & \multirow{2}{*}{2019} & \multirow{2}{*}{$\begin{array}{c}\text { Total } \\
2010 \text { a } 2019\end{array}$} \\
\hline & & & & & & & & & & & \\
\hline SP & NI & NI & NI & 87 & 490 & 1446 & 1378 & 1293 & 1233 & 7562 & 13489 \\
\hline $\mathbf{R J}^{18}$ & 427 & 424 & 407 & 324 & 369 & 308 & 429 & 373 & 376 & 404 & 3841 \\
\hline DF & 117 & 116 & 74 & 101 & 105 & 94 & 63 & 61 & 50 & 60 & 841 \\
\hline $\mathbf{G O}^{19}$ & 26 & 32 & 44 & 47 & 47 & 75 & 73 & 83 & 151 & 127 & 705 \\
\hline PB & 32 & 19 & 73 & 50 & 68 & 36 & 29 & 18 & 27 & 33 & 385 \\
\hline RO & 72 & 43 & 41 & 39 & 37 & 27 & NI & NI & 14 & NI & 273 \\
\hline $\mathbf{P A}^{20}$ & 1 & 1 & 1 & 6 & 4 & 12 & 15 & 11 & 15 & 47 & 113 \\
\hline RS & 3 & 2 & 0 & 1 & 1 & 0 & 2 & 0 & 3 & 1 & 13 \\
\hline
\end{tabular}

Fonte: Elaborada pelos autores a partir dos Serviços de Informação ao Cidadão de cada UF (2020).

Ainda a partir das 17 UFs respondentes, somente dez fizeram menção aos procedimentos adotados nos casos de cadáveres não reclamados. Aqui é importante ressaltar a diferença entre as classificações. No estado do Rio Grande do Sul houve um desentendimento inicial acerca do qual é importante destacar: a condição de sepultamento em condição de indigência não significa uma vida pretérita nessa condição, por isso a nomenclatura de morte sem identificação. Posição corroborada pelo estado de São Paulo que utiliza os termos não identificado e não reclamado ou identificado e não reclamado.

Nesse sentido, é significativo observar que as mortes com a classificação anterior não trazem uma causalidade de situação em indigência pretérita. Entretanto, a partir das poucas desagregações e respostas 
obtidas, é possível perceber que a condição de indigência em vida aparenta ser a regra. Portanto, não confundir mortes indigentes com mortes de indigentes, apesar de não ser possível realizar essa diferenciação a partir dos dados anteriores.

A consulta referente ao questionamento dos procedimentos adotados foi realizada com o objetivo de perceber os esforços institucionais na busca pela identificação do indivíduo a ser inumado. Se há guarda de material genético ou papiloscópico, se há comunicação com a área policial que investiga desaparecidos ou se há qualquer outro esforço de identificação. O quantitativo de respostas quanto aos procedimentos (somente dez) nos dá um indicativo do possível tratamento dado à situação em outras UFs. Não é possível inferir a ausência de procedimentos investigatórios nas demais UFs. Entretanto, a despeito de entender que a realidade local sempre se impõe, a ausência de uma normatização em nível federal parece trazer limitações a uma manutenção adequada na identificação desses corpos.

Por esse motivo, a pesquisa também buscou resposta a um terceiro questionamento: a receptividade da Lei $n^{\circ}$ 13.812/2019 que versa sobre o Cadastro Nacional de Pessoas Desaparecidas (BRASIL, [2019]). Entretanto, a regulamentação ainda não foi realizada, tendo em vista o veto quanto ao prazo de 90 dias para sua efetivação. Ou seja, o normativo que poderia uniformizar procedimentos por intermédio de um sistema informático que realize cruzamento de dados em nível nacional ainda não está em execução.

\section{O fator ético e a questão do pertencimento}

Pensar ética, antes da estética, parece um contrassenso na análise da presença corporal, pois a materialidade nos aparece em primeiro lugar. Mas esse estranhamento primário esconde que antes do corpo há o conceito. E aliado ao conceito há a valoração.

Assim, trata-se de dizer que antes da estética do corpo, há o conceito que se alia a uma valoração. O ser social aglutina-se, em identidades, a partir desse ethos, ou seja, dessa valoração.

O ser social não tem ontologia e, tampouco agência, semelhante ao ser individual. Esse ponto é de grande importância para que se entenda que a valoração ética pode ser distinta quando o indivíduo é consultado em sua condição unitária e quando em sua condição social. Veja, por exemplo, a situação de um assassinato realizado por policiais militares e televisionado. É possível encontrar indivíduos que não conseguiriam agir daquela maneira ao mesmo tempo em que entendem que a instituição (representada pelos policiais) tem total legitimidade na ação.

Ou seja, o ethos do ser social implica uma coerência interna que permite a violência, — o descaso ou quaisquer outros valores negativos em nível individual - sem maiores problemas morais. O questionamento que resta nesse sentido é: as instituições possuem agência que reverberam esse ethos? Percebe que não se trata de verificar a existência de intenção, mas antes, se há a possibilidade de agência, com a lembrança constante de que a não ação, o repouso ou a estaticidade são formas de ação.

Antes de respondermos ao questionamento, uma pequena digressão quanto à questão estética é relevante, pois o caminho da Teoria das Representações Sociais é importante, segundo Moscovici (2003). Entretanto, a teoria em questão tem como premissa filosófica uma epistemologia. Ou seja, há diversas representações diferentes entre o conhecimento do senso comum e o científico. Conhecimentos distintos e que variam entre distintos estamentos societais. A premissa filosófica de Moscovici reside na epistemologia como filosofia primeira, como se a base primeira da representação estivesse na aquisição do conhecimento. Prova disso reside em seus conceitos de ancoragem e objetivação. ${ }^{9}$

Inexiste qualquer problema na análise por esse caminho. Contudo, entende-se que a ética (ou ethos ${ }^{10}$ ) apresenta-se em momento anterior à epistemologia ou à estética. A coesão interna de uma sociedade mantém-se, inclusive e principalmente por suas características morais, por intermédio de uma coerência ética. Em termos de definições de teoria da verdade, a ética a qual faz-se referência é obtida a partir de uma visão coerentista (HAACK, 2002). A conhecida crítica a essa teoria, a partir da metafísica, reside na dificuldade de definir as relações de coerência. Entendemos que a partir da ética, essas relações poderão ser mais visíveis, especialmente a partir dos casos em questão.

O foco e caminho aqui escolhido utiliza outra premissa filosófica, colocada por Levinas $(1980,1997)$, para o qual a ética apresenta-se como filosofia primeira. Esse é um giro relevante e que pode trazer novo 
significado à questão. Não se trata de ignorar o tópico epistêmico por completo, mas de observar que a ética é um fundamento anterior, onde a ordem aparente só existe na coesão ética entre diversas identidades. Assim, não se pretende criticar o conhecimento apresentado nas representações simbólicas que pode ser observado nas pesquisas de campo, entretanto, acrescenta-se que a dimensão ética é mais profunda e basilar.

Assim, pode-se retomar: é possível que exista agência na instituição para que possamos atribuir-lhe responsabilidade pela sua ação ou omissão? Olhando pelo caminho de legitimação ética parece-nos ser possível encontrar essa agência em seres institucionais. Isso se replica, por exemplo, na necessária escolha entre o tratamento dado a determinado grupo de indivíduos pertencentes ou não ao normal $^{11}$ da sociedade.

Ora, e como ocorre essa valoração? Por que o indesejado ou o inadaptado pode ser tratado de forma negativa ou omissa? Nesse sentido, a noção de pertencimento parece dar-nos uma pista relevante acerca das representações coletivas quanto aos ditos indesejáveis. Há um aparente pertencimento de determinados grupos, ao mesmo tempo em que não há uma inclusão destes em um contexto maior. Destaco Agambem em sua análise sobre Badiou no que diz:

\begin{abstract}
1.5 Na teoria dos conjuntos distingue-se pertencimento e inclusão. Tem-se uma inclusão quanto um termo é parte de um conjunto, no sentido em que todos os seus elementos são elementos daquele conjunto (dizse então que $b$ é um subconjunto de $a$, e se escreve $b \subset a$ ). Mas um termo pode pertencer a um conjunto sem estar incluído nele (o pertencimento sendo a noção primitiva da teoria, que se escreve: $\mathrm{b} \in a$ ) ou, vice-versa, estar nele incluído sem pertencer a ele. Em um livro recente, Alain Badiou desenvolveu essa distinção, para traduzi-la em termos políticos. Ele faz corresponder o pertencimento à apresentação, e a inclusão à representação (re-apresentação). Dir-se-á, assim, que um termo pertence a uma situação se ele é apresentado e contado como unidade nessa situação (em termos políticos, os indivíduos singulares enquanto pertencem a uma sociedade). Dir-se-á, por sua vez, que um termo está incluído em uma situação, se é representado na metaestrutura (o Estado) em que a estrutura da situação é por sua vez contada como unidade (os indivíduos, enquanto recodificados pelo Estado em classes, por exemplo, como "eleitores"). Badiou define normal um termo que está, ao mesmo tempo, apresentado e representado (isto é, pertence e está incluído), excrescência um termo que está representado, mas não apresentado (que está, assim, incluído em uma situação sem pertencer a ela) singular um termo que está apresentado, mas não representado (que pertence sem estar incluído) (BADIOU, 1988 apud AGAMBEM, 2002, p. 31).
\end{abstract}

Assim, estamos falando dessa classe de indivíduos que pertence a uma comunidade, mas não está incluído em sua metaestrutura ${ }^{12}$. Ora, as violações a direitos ocorrem frequentemente com a população em situação de rua ${ }^{13}$, sem que o problema ético seja de fato um constrangimento. Em momento recente do governo municipal de São Paulo houve grande repercussão quanto às políticas dadas a essa população vulnerabilizada. A presença de apoio quanto às políticas higienistas tem como base uma ética que se produz a partir do encontro com o Rosto ${ }^{14}$. No entanto, é um rosto que não causa um constrangimento e uma responsabilidade, como se sugere na ética levinasiana. E isso porque há um processo interno de coerência de valores que permite diversas situações de manutenção de exclusão.

Em termos institucionais, observar a possível ausência de tratamento específico, especialmente quanto às buscas em algum banco de dados de desaparecidos, como uma política de nível nacional, nos dá uma dimensão da construção desse valor atribuído ao corpo. Ao qual anteriormente já foi negada a possibilidade de pertencimento a um grupo, por sua despossessão, por apresentar-se como corpo não proprietário nem de si nem de bens outros.

\title{
A naturalização do descarte do corpo
}

As histórias que permeiam o tema exemplificam a ausência de interesse institucional, baseado na premissa ética anterior. Como amostra dessa situação, temos o caso de São Paulo quanto aos indigentes com $R G$, conforme destaca reportagem de Ali Rocha (2016):

As matérias falavam em mais de 3 mil pessoas documentadas que haviam sido enterradas em valas de indigentes entre 1999 e 2013, depois de terem passado pelo Serviço de Verificação de Óbito (SVO) da capital. A denúncia partiu do Programa de Localização e Identificação de Desaparecidos do Ministério 
Público de São Paulo (PLID), criado em novembro de 2013 e comandado pela promotora Eliana Vendramini. O programa constatou que os serviços públicos encarregados de lidar com desaparecimentos eram muito ruins, e muitas pessoas que constavam como desaparecidas já estavam mortas havia muito tempo.

No Distrito Federal é possível encontrar situação semelhante quanto a uma pessoa que foi enterrada em situação de indigência a despeito de estar com identificação civil. A situação veio a público pela ida ao poder judiciário por parte da mãe da vítima (TRIBUNAL DE JUSTIÇA DO DISTRITO FEDERAL E DOS TERRITÓRIOS, 2014).

Se é possível a visualização de situação como as citadas anteriormente em indivíduos que têm sua identificação civil o que dizer da população em situação de rua? O foco nesse recorte encontra caminho na invisibilidade criada a partir da ausência de identificação oficial dessa população. Conforme dados do Ministério do Desenvolvimento Social (CUNHA; RODRIGUES, 2009) ${ }^{15}$, cerca de $25 \%$ desse grupo não possui qualquer documento de identificação oficial.

Outro exemplo disso nos leva ao relato de um casal em situação de rua no qual a mulher veio a falecer e, apesar de ser identificada pelo companheiro, a burocracia envolvida para que o corpo não fosse jogado em uma vala comum ${ }^{16}$ foi imensa (LAVOR, 2016). O relato destaca que a Defensoria Pública do Ceará foi acionada para que fossem realizados os exames de papiloscopia e DNA, o que permitiu, por um cruzamento de dados de um cadastro anterior em um Centro de Referência, que houvesse a identificação. Entretanto, a comprovação de união estável ainda se fazia pendente, o que demandou também mais tempo gasto no processo.

Há ainda o relato de uma mãe que ao perder seu filho em situação de violência policial, ao ser informada pela polícia, descobriu que o corpo já havia sido enterrado como indigente, a despeito da identificação papiloscópica, como nos traz o relato:

Eu não tinha com quem falar e corri para o Instituto Médico Legal na intenção de encontrar o corpo do meu filho. Para minha surpresa, ele já tinha sido sepultado como indigente. Eu fiquei muito destruída porque só me avisaram depois do processo do exame de papiloscopia [...]. Descobriram as digitais e só me avisaram depois do sepultamento. (Relato de Aparecida (nome fictício) em (BRITO, 2018, p. 70).

Esses relatos nos demonstram uma via que sinaliza uma certa naturalização do descarte. O corpo errante, vivo ou morto, seja por uma representação institucional ou popular termina por se amoldar, especialmente em contextos urbanos, como destaca Simone Frangella (2004, p. 286):

Por um lado, suportam as mazelas físicas e morais impressas pelas interdições feitas à sua presença, sofrem uma tensão latente que encurva e amarra seus movimentos, comprimem os corpos de maneira a caber nos interstícios e espaços ociosos dos quais se apropriam. Por outro, desviam dos obstáculos, moldam técnicas corporais de sobrevivência, demarcam lugares de intimidade, arranjam maneiras de saciar suas necessidades corporais, tornam-se miméticos ao espaço acomodando sua presença à paisagem urbana $\mathrm{e}$ criam visibilidades desnorteantes quando necessitam se fazer notar.

O descarte do corpo, seja em seu momento parcial (ao ignorar o corpo) ou total (ao desprezar o cadáver) nos demonstra esse incontornável ethos ao qual as instituições estão vinculadas enquanto expressão de um tempo.

No que diz respeito aos procedimentos quanto às mortes consideradas indigentes há, inicialmente, a suposição de ausência de interesse institucional no tratamento dado a esses corpos. Há uma certa naturalização ${ }^{17}$ do descarte do corpo. Percebe-se aqui que não se trata de uma omissão no sentido legal do termo, pois a matéria no direito envolve uma forma basilar de justificativa. E foi acerca dessa justificativa prévia que falamos ao longo do texto. O costume permite que o valor atribuído ao corpo não identificado seja a menor ou inexistente.

Trata-se de observar que a naturalização é permeada por uma questão que envolve elementos para além de uma suposta racionalidade, de uma agência racional que tem sua intencionalidade exposta na indiferença. Trata-se de entender que a fundamentação tem mais uma camada, envolve um certo acordo, acordo este que, pelo seu silêncio, inclui-se no âmbito desse ethos, desse lugar que é permeado igualmente por afecções e racionalizações. 


\section{Considerações finais}

Com vistas ao desfecho, o presente texto apresenta-se em caráter introdutório à questão de mortes indigentes, com vistas a demandar elementos de pesquisa posterior, tais como: os procedimentos em nível regional e sua ausência de uniformização, a negação ao direito ao velamento (seja religioso ou cerimonial), uma análise etnológica das famílias envolvidas, dentre outros elementos possíveis.

É importante ressaltar que o recorte teórico aqui utilizado, como dito anteriormente, pode utilizar-se de análises que transcendam à questão ética, atualizando a questão da representação social (em nível epistemológico) ou mesmo do direito, ou seja, em nível deontológico, no sentido daquilo que a instituição deve fazer.

Observar a realidade histórica que nos é imposta por intermédio de uma perspectiva moral (ou ethologica) prospecta caminhos para o entendimento que a agência estatal pode não ter sua deliberação (o que chamaríamos de consciência em nível individual) como uma própria vontade em si, mas como uma não vontade que se expressa no desinteresse apresentado ao longo do texto.

Percebamos que não se trata de entrar na potencial mais próxima e consequente análise de que a falta de ação já é uma ação por si. Trata-se de observar que a ausência de ação não necessariamente pressupõe uma intencionalidade ou que isso só é relevante em um segundo momento. Ou seja, significa perceber que as estruturas de exclusão, por vezes, estão além do binômio ação/inação ou intencionalidade/fatalidade natural, mas se estendem no vasto campo dos juízos de valores e nas relações de pertencimento entremeadas e porosas de sociedades.

\section{Referências}

AGAMBEM, G. Homo Sacer: o poder soberano e a vida nua I. Belo Horizonte: Ed. da UFMG, 2002.

BRASIL. Lei no 13.812/2019 de 16 de março de 2019. Institui a Política Nacional de Busca de Pessoas Desaparecidas, cria o Cadastro Nacional de Pessoas Desaparecidas e altera a Lei no 8.069, de 13 de julho de 1990 (Estatuto da Criança e do Adolescente). Brasília, DF: Presidência da República, [2019]. Disponível em: http://www.planalto.gov.br/ccivil_03/_ato2019-2022/2019/lei/L13812.htm. Acesso em: 18 dez. 2020.

BRASIL. Lei no 8.501/921992. Dispõe sobre a utilização de cadáver não reclamado, para fins de estudos ou pesquisas científicas e dá outras providências. Brasília, DF: Presidência da República, [1992]. Disponível em: http://www.planalto.gov.br/ccivil_03/Leis/ L8501.htm. Acesso em: 18 dez. 2020.

BRITO, M. de D. Não. Ele não está. Curitiba: Appris, 2018.

CUNHA, J. V. Q. da; RODRIGUES, M. Rua aprendendo a contar. Brasília, DF: Ministério do Desenvolvimento Social e Combate à Fome. Disponível em: http://www.mds.gov.br/webarquivos/publicacao/assistencia_social/Livros/Rua_aprendendo_a_contar.pdf. Acesso em: 18 dez. 2020.

DIANA, G. M. O Debate entre o Não-Cognitivismo e o Cognitivismo Moral. 2004. 90 f. Dissertação (Mestrado em Filosofia) Universidade de Brasília (UnB), 2004.

DURKHEIM, É. As regras do método sociológico. São Paulo, SP: Editora Nacional, 1987.

FRANGELLA, S. M. Corpos urbanos errantes: uma etnografia da corporalidade de moradores de uma rua em São Paulo. 2004. 361 f. Tese (Doutorado)-Universidade Estadual de Campinas, Instituto de Filosofia e Ciências Humanas, Campinas, SP. Disponível em: http://www.repositorio.unicamp.br/handle/REPOSIP/279907. Acesso em: 18 dez. 2020.

HAACK, S. Filosofia das Lógicas. São Paulo, SP: Ed. da UNESP, 2002.

LAPA, R. S. A alteridade como fundamento para uma teoria crítica de direitos humanos. 2017. 107 f. Dissertação (Mestrado em Direitos Humanos e Cidadania)-Universidade de Brasília (UnB), Brasília, 2017.

LAVOR, T. "Invisíveis até na morte": a luta de um morador de rua para evitar que sua mulher fosse enterrada como indigente. BBC Brasil, Fortaleza, 2016. Disponível em: https://www.bbc.com/portuguese/brasil-38095909. Acesso em: 18 dez. 2020.

LEOPOLDO E SILVA, F. A negação do sujeito. In: LEOPOLDO E SILVA, F. Mutações. Fontes Passionais da Violência. Rio de Janeiro. Artepensamento. 2014.

LEVINAS, E. Entre Nós: Ensaios sobre a alteridade. Petrópolis, RJ: Vozes, 1997.

LEVINAS, E. Totalidade e infinito. Lisboa: Edições 70, 1980.

MERLINO, T. Entrevista: Júlio Lancellotti: "Há uma ação de extermínio dos moradores de rua”. Carta Capital, São Paulo, SP, 2018. Disponível em: https://www.cartacapital.com.br/sociedade/julio-lancellotti-ha-uma-acao-de-exterminio-dos-moradores-de-rua. Acesso em: 18 dez. 2020. 
MOSCOVICI, S. Representações sociais: investigações em psicologia social. Rio de Janeiro, RJ: Vozes, 2003.

ROCHA, A. Indigente em São Paulo. A Publica, São Paulo, nov. 2016. Disponível em: https://apublica.org/2016/11/indigenteemsp/. Acesso em: 18 dez. 2020.

SICARI, A.; ZANELLA, A. V. Pessoas em Situação de Rua no Brasil: Revisão Sistemática. Psicol. cienc. Prof., Brasília, v. 38, n. 4, p. 662-679, out. 2018.

TRIBUNAL DE JUSTIÇA DO DISTRITO FEDERAL E DOS TERRITÓRIOS. DF terá que indenizar mãe cujo filho foi enterrado como indigente mesmo portando documentos. Brasília, DF: TJDFT, out. 2014. Disponível em: https://www.tjdft.jus.br/institucional/ imprensa/noticias/2014/outubro/df-tera-que-indenizar-mae-cujo-filho-foi-enterrado-como-indigente-mesmo-portando-documentos. Acesso em: 18 dez. 2020.

\section{Notas}

1 Essas quatro últimas definições são trabalhadas no método de genealogia conceitual realizado por Agambem (2002).

2 Vale a pena maior aprofundamento desse recorte, tendo em vista pesquisas quanto à subjetividade advinda da noção de trabalho entre a população em situação de rua, já que alguns deles não consideram trabalhos, incontornáveis à própria sobrevivência, como a de vigia de carros ou de catadores de materiais recicláveis, como elementos que os colocam em posição de ocupantes de um status de trabalhador (SICARI; ZANELLA, 2018).

3 É salutar indicar que o termo indigente no contexto do falecimento é considerado pejorativo pelos atores indicados nesta pesquisa. Isso talvez ocorra pela diferença entre a condição de ausência de identificação e não reclamação do corpo e a condição anterior de indigência social. É importante ressaltar que o contexto de pesquisa se baseia, no caso brasileiro, na definição disposta na Lei $n^{\circ}$ 8.501/92 (BRASIL, 1992) que, por sinal, tem por objetivo estabelecer os casos em que o cadáver não reclamado possivelmente será destinado para fins de estudo e pesquisa.

4 Protocolo eSIC/CGU 25820.005734/2017-17.

5 A primeira resposta foi concedida em janeiro de 2018, por intermédio do Protocolo e-SIC/GDF 00052000128201714 (Memorando $n^{\circ} 66 / 2018$ - IML).

6 Protocolo e-SIC/GDF 00052000040201883.

7 Nesse sentido, cumpre informar que AC, AP, AM, MT, PI, RR, SE e TO não encaminharam resposta alguma sobre os questionamentos da pesquisa.

8 Algumas UFs informaram dados parciais somente quanto ao procedimento adotado no caso de cadáveres não reclamados.

9 Os dois processos são referentes à construção do conhecimento. Ou seja, tratam de uma questão primariamente epistêmica.

10 Perceba que o uso de ética, moral e ethos tem-se confundido ao longo da escrita. Entretanto, é relevante fazer a seguinte marcação: moral e ética serão utilizados como palavras correlatas e intercambiáveis no contexto desta curta pesquisa. Entende-se a ética aqui em um sentido cognitivista, ou seja, nos quais é possível que enunciados éticos sejam avaliados em termos de verdade, tendo em vista uma possível taxonomia ética. (DIANA, 2004, p. 61). O ethos, entretanto, refere-se a essa dimensão da ética aplicada ao ser social.

11 Pensando aqui na definição durkheimiana que coloca o normal com elementos de regularidade ou generalidade (DURKHEIM, 1987).

12 A metaestrutura a que Agamben (2002) faz referência, nesse caso diz respeito ao Estado. Metaestrutura, no sentido marxista, diz respeito a esse momento abstrato que dá sustentação a uma determinada estrutura. No caso marxista, uma estrutura mercantil, que também tem bases no Estado, sem dúvida. No caso de Agambem, uma estrutura hierarquizante.

13 Recentemente Júlio Lancelloti explicita o que ele chama de "ação de extermínio de moradores de rua” quanto às ações das subprefeituras da cidade de São Paulo (MERLINO, 2018).

14 Trata-se de um conceito levinasiano que diz respeito à apresentação do Outro, do ente por excelência.

15 Destaque-se a ausência de estudos mais recentes quanto à questão.

16 Há muito que se falar na observação do contexto representacional acerca da simbologia do direito ao velamento, à identificação do corpo e a sua questão religiosa/espiritual.

17 Por natural queremos dizer o movimento de percepção do inescapável. Ou seja, é entendido que há uma necessária fatalidade para que determinado grupo de pessoas se mantenha nessa situação, seja por uma condição religiosa, metafísica ou científica (LAPA, 2017, p. 51).

18 O estado do Rio de Janeiro apresentou os dados com desagregação referente ao sexo, do qual destaca-se que do total tem-se 3.414 pessoas do sexo masculino e 427 pessoas do sexo feminino. 
19 O estado de Goiás também apresentou os dados desagregados para sexo e raça, acerca do qual destacamos: (i) quanto ao sexo: 621 - masculino, 68 - feminino e 16 - não informado; (ii) quanto à raça: 15 - negro, 103 - pardo, 17 - branco e 570 - não informado.

20 O estado do Pará, por sua vez, apresentou os dados de forma desagregada para sexo e idade, além dos municípios e crimes vinculados. Para os fins desta pesquisa destacamos somente a desagregação por sexo: 97 -masculino, 5 - feminino e 11 - não informado.

21 Há diferença entre os dados trazidos nessa primeira solicitação e os dados dispostos na Tabela 1. Optou-se por manter a discrepância dos dados como indicação de possíveis ausências de tratamento fino à situação específica.

\title{
Raphael Santos Lapa
}

raphaelsantoslapa@gmail.com

Mestre em Direitos Humanos pela Universidade de Brasília (UnB)

Doutorando em Sociologia na Universidade de Brasília (UnB)

\section{UnB}

Campus Darcy Ribeiro

Brasília - DF - Brasil

CEP: 70910-900

\section{Gilson Matilde Diana}

gilson.gmd@gmail.com

Mestre em Filosofia pela Universidade de Brasília (UnB)

Doutorando em Direito pela Universidade de Brasília (UnB)

Professor do Programa de Pós-Graduação da Academia Nacional de Polícia (ANP)

\author{
ANP \\ Rodovia DF $001 \mathrm{KM}-02$ \\ Brasília - DF - Brasil \\ CEP: 71559-900
}

\section{Agradecimentos}

Não se aplica.

Agência financiadora

Não se aplica.

\section{Contribuições dos autores}

$\mathrm{O}$ artigo foi escrito em coautoria e trata de temática de interesse de ambos autores, especialmente no que diz respeito ao campo de ética e moral. A coleta e tratamento de dados teve uma maior participação de R. S. Lapa. Os demais elementos do texto foram produzidos, por completo, com participação de ambos autores.

Aprovação por Comitê de Ética e consentimento para participação

Não se aplica.

Consentimento para publicação

Consentimento dos autores.

Conflito de interesses

Não há conflito de interesses. 